\title{
Hot Coal Gas Desulfurization With Manganese-Based Sorbents
}

\section{Topical Report}

M. T. Hepworth

R. Ben-Slimane

December 1994

Work Performed Under Contract No.: DE-AC21-92MC29246

For

U.S. Department of Energy

Office of Fossil Energy

Morgantown Energy Technology Center

Morgantown, West Virginia

By

University of Minnesota

Minneapolis, Minnesota

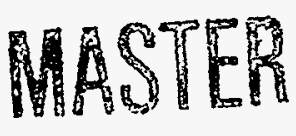

$J R$ 


\section{DISCLAIMER}

\section{Portions of this document may be illegible in electronic image products. Images are produced from the best available original document.}




\title{
Hot Coal Gas Desulfurization With Manganese-Based Sorbents
}

\author{
Topical Report
}

M. T. Hepworth

R. Ben-Slimane

Work Performed Under Contract No.: DE-AC21-92MC29746

For

U.S. Department of Energy

Office of Fossil Energy

Morgantown Energy Technology Center

P.O. Box 880

Morgantown, West Virginia 26507-0880

By

University of Minnesota

Department of Civil and Mineral Engineering

500 Pillsbury Drive, SE.

Minneapolis, Minnesota 55455-0220

December 1994

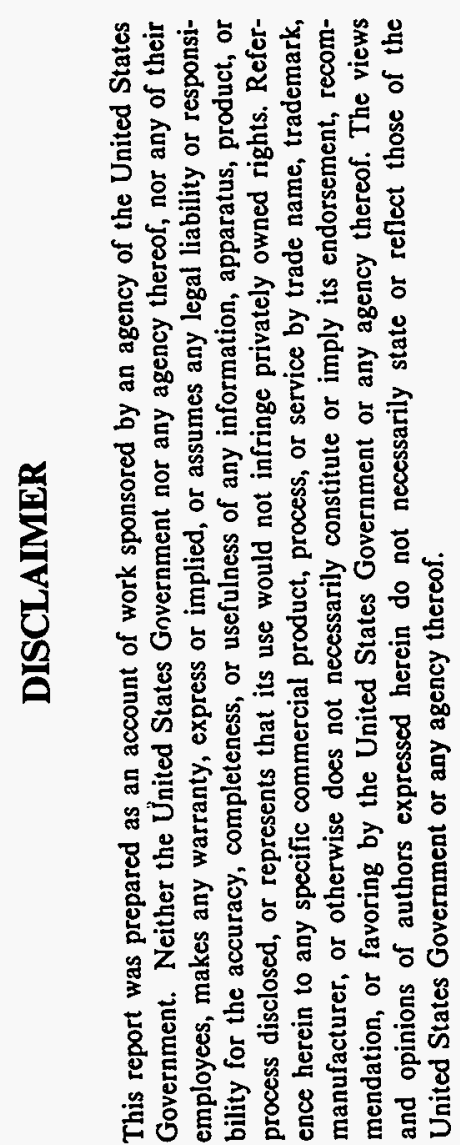




\begin{abstract}
The focus of work being performed on Hot Coal Gas Desulfurization at the Morgantown Energy Technology Center is primarily in the use of zinc ferrite and zinc titanate sorbents; however, prior studies at the U. S. Steel Fundamental Research Laboratories in Monroeville, PA, by E. T. Turkdogan ${ }^{1}$ indicated that an alternate sorbent, manganese dioxidecontaining ore in mixture with alumina ( $75 \mathrm{wt} \%$ ore $+25 \mathrm{wt} \% \mathrm{Al}_{2} \mathrm{O}_{3}$ ) may be a viable alternative to zinc-based sorbents. Manganese, for example, has a lower vapor pressure in the elemental state than zinc hence it is not as likely to undergo depletion from the sorbent surface upon loading and regeneration cycles. Also manganese oxide is less readily reduced to the elemental state than iron hence the range of reduction potentials for oxygen is somewhat greater than for zinc ferrite. In addition, thermodynamic analysis of the manganese-oxygen-sulfur system shows it to be less amenable to sulfation than zinc ferrite. Potential also exists for utilization of manganese at higher temperatures than zinc ferrite or zinc titanate.
\end{abstract}

This Annual Topical Report documents progress in pelletizing and testing via thermo-gravimetric analysis of individual pellet formulations of manganese ore/ alumina combinations and also manganese carbonate/ alumina with two binders, dextrin and bentonite. The major accomplishments are given in an attached paper which is being prepared for publication in Energy and Fuels.

\footnotetext{
${ }^{1}$ Turkdogan, E. T. and Olsson, R. G.: "Desulfurization of Hot Reducing Gases with Manganese Oxide Pellets", Proceedings Third International Iron and Steel Congress ASM Metals Park, Ohio, 1979, pp.277-288.
} 


\title{
Desulfurization of Hot Coal-Derived Fuel Gases with Manganese-Based Regenerable Sorbents. 3. Fixed-Bed Testing
}

\author{
R. Ben-Slimane" and M. T. Hepworth"* \\ Department of Civil and Mineral Engineering, University of Minnesota, \\ 500 Pillsbury Drive, S.E., Minneapolis, Minnesota 55455-0220
}

In recent studies, the thermodynamic feasibility of using manganese-based sorbent pellets for the removal of $\mathrm{H}_{2} \mathrm{~S}$ from hot-coal derived fuel gases, and the subsequent regeneration of loaded (sulfided) pellets with air was established. Screening sulfidation tests on a number of formulations, consisting of a manganese-containing compound (ore or $\mathrm{MnCO}_{3}$ ), alundum $\left(\mathrm{Al}_{2} \mathrm{O}_{3}\right)$, and organic or inorganic binders, were carried out using $\mathrm{H}_{2} \mathrm{~S}-\mathrm{H}_{2}$ gas mixtures in a thermogravimetric apparatus (TGA) at temperatures ranging from 700 to $1000^{\circ} \mathrm{C}$. A formulation, designated FORM4-A, was found to possess the best combination of sulfur capacity, reactivity, and strength. Regeneration tests determined that for $\mathrm{T} \geq 900^{\circ} \mathrm{C}$, loaded pellets can be fully regenerated with air in 10 to 15 minutes, without sulfate formation. This paper reports on fixed-bed testing of the leading Mn-based sorbent pellet formulation (i.e., FORM4-A). Experiments are carried out to test the long-term durability and regenerability of the sorbent using a simulated Tampella-U fuel gas for sulfidation and air for regeneration. In addition, the effect of temperature on sulfidation reaction equilibrium is determined in the range 800 to $1000^{\circ} \mathrm{C}$. A re-assessment of the equilibrium states of reactions involving solid $\mathrm{MnO}, \mathrm{MnS}, \mathrm{Mn}_{3} \mathrm{O}_{4}$, and $\mathrm{MnSO}_{4}$ is then presented based on the results obtained and a recent study by Turkdogan.

\footnotetext{
- Post-Doctoral Associate; author to whom correspondence should be addressed.

** Professor.
} 


\section{Introduction}

The rationale for desulfurizing coal-derived fuel gases at high temperature is a result of concerns within the U.S. Department of Energy to burn coal to produce electrical power more efficiently and also to meet government regulations for sulfur emissions which have become progressively more stringent.

Conventional technology of power generation is inherently inefficient and consists of reacting coal in a burner system which exchanges heat to a boiler to generate steam. This steam then passes through a turbine to drive a generator and produce electricity. The sulfur in the coal is released in form of sulfur dioxide $\left(\mathrm{SO}_{2}\right)$ in the flue gas. The removal of $\mathrm{SO}_{2}$ from the flue gas prior to discharge into the atmosphere is essential to prevent air pollution. Conventional processes for sulfur recovery are well established and require that the coal gas be cooled to less than $100^{\circ} \mathrm{C}$ in order to contact it with scrubbing reagents.

The loss of thermal efficiency in the cooling process lowers the energy available for electrical conversion compared with the higher efficiencies which would be obtained if the coal gas were desulfurized while hot. In addition, since the volume of the fuel gas stream is significantly less than that of the flue gas stream, particularly since it is usually also at elevated pressure, the removal of sulfur-bearing species at high temperature results in considerably lower hardware costs. Also, conventional $\mathrm{SO}_{2}$ scrubbing results in the formation of gypsum sludge, which requires costly management. A regenerable sorbent avoids this problem since the sulfur can be recovered as sulfur dioxide or other sulfur products. The cleaned hot fuel gas may then be useful in a number of applications such as an integrated gasification combined cycle (IGCC), an emerging energy conversion system to produce electrical power at higher efficiencies than those experienced in conventional steam plants. Power generation may also be rendered more efficient by ultimately by-passing Rankine efficiencies completely and using the generated fuel gases in fuel cells for the direct conversion of heat into electricity. The problem with operation of fuel cells or IGCC systems, which are principally based on coal gasification, is that sulfur must be removed at high temperature to prevent 
its corrosive effects.

For the reducing conditions which are encountered in gasifiers operating on coal combustion systems, the predominant sulfur-bearing gaseous species is $\mathrm{H}_{2} \mathrm{~S}^{1,2,3}$ The conventional technology of scrubbing the gas for $\mathrm{H}_{2} \mathrm{~S}$ is not practical in these situations because the scrubbing processes operate at low temperature and, therefore, impose severe penalties relating to thermodynamic losses and heat transfer equipment cost. For maximum efficiency, the IGCC process must employ hot-gas cleanup techniques to remove sulfur and other impurities in the fuel gas stream. This approach completely eliminates the more costly, less efficient method in which a liquid-based scrubbing system is employed at low-temperatures for scrubbing the flue gas.

Desulfurization with sorbents is essentially a process of removal of the $\mathrm{H}_{2} \mathrm{~S}$ species from the gas phase. As $\mathrm{H}_{2} \mathrm{~S}$ is removed, the other minority sulfur-bearing species, such as COS, equilibrate in the gas phase and also are proportionately reduced. ${ }^{1}$ The high temperature desulfurization can be successfully accomplished by using solid sorbents such as oxides of those metals that form stable sulfides. The effectiveness of a desulfurizing agent in treating coal gases is related to the predicted equilibrium partial pressure of sulfur which will be present in a phase combination of the reduced form of sulfide and oxide phases. A sulfur concentration limitation of approximately $150 \mathrm{ppmv}$ (parts per million by volume) for IGCC systems has been established; therefore, a sorbent system capable of reducing $\mathrm{H}_{2} \mathrm{~S}$ concentration from about 5000 to 150 ppmv or lower is sought. ${ }^{4}$ The focus of much current work on hot coal-derived fuel gas desulfurization is primarily in the use of zinc ferrite and zinc titanate sorbents. The choice of zinc oxide is typically based on the thermodynamic considerations that indicated very low concentration levels of $\mathrm{H}_{2} \mathrm{~S}$ in equilibrium with $\mathrm{ZnO}, \mathrm{ZnS}$, and $\mathrm{H}_{2} \mathrm{O}$ vapor. ${ }^{5}$

To improve the process economics further, an easily regenerable sorbent is required which would not only reduce sorbent costs but also costs associated with frequent loading and unloading of the reactors with sorbent and disposal of the spent sorbent. Furthermore, the sulfur produced by regeneration of the sorbent 
should be recoverable in a form which is readily saleable, storable, or disposable. This means that the regeneration step should be flexible and be able to produce elemental sulfur or sulfuric acid depending upon the demand at the location of the gasification plant. With these restrictions in mind, research has focused almost entirely on making the zinc-based sorbents durable. However, extensive research, carried out mainly by the Morgantown Energy Technology Center (METC), casts doubt that zinc ferrite or zinc titanate can be utilized even for the mild conditions associated with fixed-bed operation. The desirable properties of $\mathrm{Zn}$-based sorbents as well as their practical limitations have been discussed in detail by Ben-Slimane and Hepworth. ${ }^{6,7}$

Given the limited success of the zinc-based sorbents, interest has been shown in formulating and testing manganese-based sorbent pellets. ${ }^{8}$ The thermodynamic feasibility of using such sorbent pellets for the removal of $\mathrm{H}_{2} \mathrm{~S}$ from hot coal-derived fuel gases, and the subsequent regeneration of loaded (sulfided) pellets with air has been previously discussed in detail. ${ }^{6,7}$ Screening sulfidation tests on a number of formulations were carried out using $\mathrm{H}_{2} \mathrm{~S}-\mathrm{H}_{2}$ gas mixtures in a thermogravimetric apparatus (TGA) in the temperature range 700 to $1000^{\circ} \mathrm{C}$. These formulations consisted of a manganese-containing compound (ore or $\mathrm{MnCO}_{3}$ ), alundum $\left(\mathrm{Al}_{2} \mathrm{O}_{3}\right)$, and organic or inorganic binders. $\mathrm{A}$ formulation, FROM4-A as described below, was found to possess the best combination of sulfur capacity, reactivity, and strength. Regeneration tests were carried out on loaded pellets and determined that for $\mathrm{T} \geq 900^{\circ} \mathrm{C}$, FORM4-A pellets could be fully regenerated with air in 10 to 15 minutes.

Repeated cycling of the leading sorbent formulation (FORM4-A) was conducted in the TGA apparatus, up to five consecutive cycles. One important finding was that the capacity of the pellets for sulfur pickup from fuel gas and the kinetics of reduction, sulfidation, and regeneration improved with recycling without compromising the strength. This desirable phenomenon was attributed to radial micro-crack formation which reduced the solid-state diffusion path within the pellet. Normally, and especially in the case of $\mathrm{Zn}$-based sorbents, the onset of 
small cracks leads to sorbent spalling and reduced usable life due to increased "dust" loadings in an exit gas stream. ${ }^{9}$ With the Mn-based sorbents, the presence of these small cracks apparently led to improvement in the reaction rate for sulfidation and regeneration without adversely affecting the strength.

While the results reported earlier ${ }^{6,7}$ were obtained using thermogravimetry, the potential usefulness of Mn-based pellets may be more realistically assessed by simulating practical processes of fuel gas desulfurization, which fall into three main categories: fixed-bed, fluidized-bed, or moving-bed technology. This paper reports on fixed-bed testing of the leading Mn-based sorbent pellet formulation (i.e., FORM4-A). Experiments are carried out to test the long-term (up to 14 cycles) durability and regenerability of the sorbent using a simulated Tampella-U fuel gas for sulfidation and air for regeneration. In addition, the effect of temperature on sulfidation reaction equilibrium is determined in the range 800 to $1000{ }^{\circ} \mathrm{C}$. A re-assessment of the equilibrium states of reactions involving solid $\mathrm{MnO}, \mathrm{MnS}, \mathrm{Mn}_{3} \mathrm{O}_{4}$, and $\mathrm{MnSO}_{4}$ is then presented based on the results obtained and a recent study by Turkdogan. ${ }^{10}$

\section{Experimental Investigations and Results}

\section{Introduction}

The procedures for sorbent pellet making, drying, and induration are fully documented in a recent patent application filed by the authors. ${ }^{11}$ However, the test work reported in this paper is directed only to formulation FORM4-A which was shown to possess the most favorable loading characteristics of the four formulations selected for screening sulfidation tests. This formulation is made up of $81.31 \%$ by weight manganese carbonate (containing $93-95 \% \mathrm{MnCO}_{3}$ ), $16.73 \%$ alundum (containing $96.6 \% \mathrm{Al}_{2} \mathrm{O}_{3}$ and $2.6 \% \mathrm{TiO}_{2}$ ), and $1.96 \%$ bentonite (an inorganic binder). Upon forming pellets, they were first dried to a constant weight at $110^{\circ} \mathrm{C}$, then heated to $350^{\circ} \mathrm{C}$ to allow for dissociation of the manganese carbonate. The pellets were then heated to $1250^{\circ} \mathrm{C}$ and indurated

$\cdot \mathrm{MnCO}_{3}$ dissociates to $\mathrm{MnO}$ and $\mathrm{CO}_{2}$ at $343^{\circ} \mathrm{C}$ with $\mathrm{CO}_{2}$ evolving at 1 atm. 
for 2 hours in an air atmosphere before removal from the furnace. The average size of the pellets was $4.8 \mathrm{~mm}$ and they had an average strength of $23.8 \mathrm{~N} / \mathrm{mm}$ of diameter $(5.4 \mathrm{lbs} / \mathrm{mm})$. The final manganese assay of the indurated pellets was $44.22 \%$ by weight, which corresponds to a theoretical sulfur capacity of $25.8 \%$, i.e., $25.8 \mathrm{gS} / 100 \mathrm{~g}$ of indurated pellet.

\section{Fixed-Bed System Description and Testing Procedures}

The schematic diagram of the overall experimental arrangement for fixedbed tests is shown in Figure 1. The split or two-zone furnace is positioned with respect to the bed to accomplish gas preheating and careful control of the bed temperature. Gas combinations for flows are produced via control of bottled gases through the valves and flowmeters shown in the diagram. The water content of the system is controlled by a metering pump acting on distilled water which is discharged into a heated stainless steel tube to induce the vaporization of liquid water and provide the gas composition required for the simulation of a slightly modified form of the Tampella- $U$ gas (from a Tampella- $U$ air-blown gasifier), as reported in Table 1. Hydrogen sulfide is mixed with the other gases and water vapor immediately before the introduction of the complete mixture into the reactor to minimize corrosion of system components. The reactive gas feed line was heat-traced to prevent subsequent condensation. In addition, the exhaust gas line was also heated from the top of the reactor to the cold trap to prevent any formation and subsequent freezing of elemental sulfur.

The primary modification made in the gas composition is an.increase in the amount of $\mathrm{H}_{2} \mathrm{~S}$, which is typically contained at about $1 \%$ by volume in Tampella $\mathrm{U}$-gas. The modified composition included $3 \%$ by volume of $\mathrm{H}_{2} \mathrm{~S}$ to decrease the amount of time required to achieve "breakthrough", arbitrarily defined at $\left[\mathrm{H}_{2} \mathrm{~S}\right]=$ $500 \mathrm{ppmv}$ in the exit gas. Tampella-U gas also contains $0.111 \% \mathrm{NH}_{3}$ and $1.84 \%$ 
Table 1. Gas Composition for the Simulation of the Tampella-U Fuel Gas.

Gas

$\begin{array}{lr}\text { Hydrogen }\left(\mathrm{H}_{2}\right) & 13 \\ \text { Nitrogen }\left(\mathrm{N}_{2}\right) & 50 \\ \text { Carbon monoxide }(\mathrm{CO}) & 24 \\ \text { Carbon dioxide }\left(\mathrm{CO}_{2}\right) & 5 \\ \text { Water vapor }\left(\mathrm{H}_{2} \mathrm{O}\right) & 5 \\ \text { Hydrogen sulfide }\left(\mathrm{H}_{2} \mathrm{~S}\right) & 3\end{array}$

$\mathrm{CH}_{4}$, which are not taken into consideration in the present study.

The Tampella-U gas was selected for experimentation, in part, because of its relatively low water vapor content $(\approx 5 \%$ by volume). The extent of desulfurization attainable with a $\mathrm{Mn}$-based sorbent is dependent on the water vapor content of the feed gas, i.e., lower water vapor content results in higher levels of desulfurization. In addition, the choice of a fuel gas having a low water vapor content should, actually, be indicative of the performance of the sorbent pellets because gasifier systems typically add water vapor to the exit gas stream to stabilize zinc oxide and render the desulfurization with zinc-based sorbents possible. Also, in order to prevent carbon formation in the desulfurizer, a large quantity of steam must be added to the fuel gas. If a Mn-based sorbent is used, the water addition can be eliminated altogether, which would provide additional advantages as addition of water vapor poses two major disadvantages. First, the heating value of the exit gas is significantly reduced with the introduction of water vapor and, second, the volume of the gas is increased which requires corresponding increases in the size and cost of the equipment in the desulfurization system and other equipment downstream. ${ }^{12}$

The details of the fixed-bed reactor system are depicted in Figure 2. This figure shows the two-inch (I.D.) closed-end alumina reactor tube equipped with an alumina perforated-disc plate suspended over alumina chips. The simulated coalderived fuel gas is passed through a small central tube (without contacting the reaction zone of manganese-based pellets) through the perforated disc and into a 
preheat zone of alumina chips which supports the disc. The gas is then discharged from the small central tube into the larger tube and moves upward into a gas preheat zone of the two-zone furnace. The gas, now at the desired temperature, ranging from 800 to $1000^{\circ} \mathrm{C}$, then contacts the sorbent bed consisting of FORM4-A pellets ranging in size from 4 to $5 \mathrm{~mm}$ in diameter. The off-gas is then flared and passed through a cold trap to condense water vapor before being scrubbed in a sodium hypochlorite solution and then discharged into a hood. A gas sample is taken via a sampling bag prior to scrubbing and is analyzed for $\mathrm{H}_{2} \mathrm{~S}$ using detector tubes which have been calibrated using pre-mixed $\mathrm{H}_{2} \mathrm{~S}-\mathrm{N}_{2}$ gas mixtures. Detector tube readings were also checked by an independent wet chemistry method which consisted of determining the $\mathrm{H}_{2} \mathrm{~S}$ concentration in the exhaust gas by periodically bubbling the gas through an aqueous solution of lead acetate and measuring the quantity of material precipitated. In addition, feed and exit gas flowrates were calibrated using a wet test meter.

The fixed-bed was made with 292.7 grams of FORM4-A pellets packed to a height of $15.24 \mathrm{~cm}$ (6 inches) in the 2 -in (I.D.) reactor tube. In a typical test, the reactor was purged with nitrogen to expel air. During the purge, reactive gas flows were adjusted and routed directly to the scrubber solution. The reactive gases were then introduced into the reactor and the loading test timed. In such a fixed-bed desulfurization reactor, $\mathrm{H}_{2} \mathrm{~S}$ removal would first occur near the bottom of the bed where reduction of $\mathrm{Mn}_{3} \mathrm{O}_{4}$ to $\mathrm{MnO}$ and the immediate conversion of $\mathrm{MnO}$ to $\mathrm{MnS}$ occur. The majority of the unreacted pellets are then exposed to the sulfur-free reducing gas for varying times as the reaction front progressed through the bed.

At the conclusion of the sulfidation test, the bed is flushed with nitrogen in order to expel remaining combustible gases and a regeneration gas consisting of air is initiated, with the product gas being periodically analyzed for $\mathrm{SO}_{2}$ using detector tubes. The regeneration step is discontinued when the measured concentration of $\mathrm{SO}_{2}$ is below 500 ppmv. 
A minor problem arose in preliminary regeneration tests, which were carried out with air at $3 \mathrm{~L} / \mathrm{min}$, in that sulfur tended to deposit in the exhaust lines. Its accumulation during the early stages of regeneration caused plugging of the exit tube (close examination revealed that it was elemental sulfur). This indicates that the oxygen in the regeneration air was completely consumed. In addition, examination of the pellets showed them to have experienced extreme overheating which led to sintering and loss of reactivity. These problems were overcome by reducing the air flowrate in order to limit the rate of heat release by the highly exothermic regeneration reaction. The addition of an after-burner on top of the pellet bed resulted in more oxidizing conditions and hence less tendency for sulfide sulfur $\left(S^{=}\right)$to oxidize to the intermediate elemental form $\left(S^{\circ}\right)$ rather than to the 4-valent $\left(\mathrm{S}^{+4}\right)$ form.

\section{Results and Discussion}

The breakthrough curve for sulfidation at $900^{\circ} \mathrm{C}$ on the first cycle is shown in Figure 3. The concentration of $\mathrm{H}_{2} \mathrm{~S}$ in the exhaust gas (on wet basis) appears to reach a steady state value of approximately $222.5 \mathrm{ppmv}$ for at least the first 7 hours of the loading test. This value is close to that of the $\mathrm{MnO} / \mathrm{MnS}$ equilibrium, which may be calculated using subsequent analysis as $256 \mathrm{ppmv}$, based on results obtained in this study (see equation (8)). The vertical dashed line corresponds to the theoretical time required for breakthrough and is a function of the quantity of sorbent pellets in the reactor, the loading gas flowrate or space velocity, and the equilibrium $\mathrm{pH}_{2} \mathrm{O} / \mathrm{pH}_{2} \mathrm{~S}$ in the exhaust gas, i.e. reaction temperature since the amount of water vapor in the feed gas is fixed at $5 \%$ by volume. If breakthrough is arbitrarily defined at $500 \mathrm{ppmv}$ in the exhaust gas, then breakthrough occurred after a total reaction time of 8 hours which corresponds to $21.12 \%$ loading or $81.86 \%$ bed utilization.

The concentration of $\mathrm{SO}_{2}$ in the regeneration product gas is shown in Figure 4 as a function of reaction time. Again, the theoretical time for complete regeneration is displayed as a vertical dashed line which is a function of air 
flowrate, the quantity of pellets in the reactor, and temperature to a lesser extent since the reaction occurs essentially to completion. In addition, the theoretical maximum $\mathrm{SO}_{2}$ concentration in the product gas (before mixing with after-burner gas) is shown in Figure 4 as a horizontal dashed line. This $13.76 \%$ value corresponds to regeneration with air and the complete consumption of oxygen in the air, and is calculated based on the stoichiometry of the overall regeneration reaction, as previously outlined in detail. ${ }^{7}$ As can be seen in Figure 4, the breakthrough occurred rapidly when the bed was almost completely regenerated.

A relatively short series of complete sulfidation/regeneration cycles was then carried out at $900^{\circ} \mathrm{C}$ to verify the sorbent as a viable candidate for fixed-bed fuel gas desulfurization. Six consecutive cycles over a 15-day period were deemed adequate for this purpose. The results of sulfidation tests from cycles 1,2,3, and 6 are reported in Figure 5. Before breakthrough the $\mathrm{H}_{2} \mathrm{~S}$ concentration in the cleaned gas approaches more closely the equilibrium value, which is an indication of an improvement in pellet reaction kinetics with increasing cyclic loading. These results are consistent with the previous results from TGA tests on individual pellets. ${ }^{7}$

A fourteen-cycle series of tests was then completed to demonstrate the durability and regenerability of FORM4-A sorbent formulation. Each sulfidation and regeneration repeated the initial run conditions. The results are reported in Figure 6 which shows the effect of cycling on the sulfur capacity of FORM4-A pellets at $900{ }^{\circ} \mathrm{C}$ upon repeated loading and regeneration. The sulfur loading capacity (defined as grams of sulfur per 100 grams of original pellet mass) shows a slight improvement with each cycle. This effect is noticeable in the second cycle, but is much less pronounced in subsequent cycles. The sulfur capacity ranged from $21.12 \%$ to $23.12 \%$, which corresponds to approximately $90 \%$ sorbent bed utilization. This sulfur capacity is calculated using mass balances, based upon gas analyses for $\mathrm{H}_{2} \mathrm{~S}$ entering and leaving the reactor. In subsequent tests, not reported here, no significant diminution in sorbent capacity was observed after twenty-five loading and regeneration cycles. 


\section{Re-assessment of Reaction Equilibria in the Solid Mn-S-O System}

Turkdogan ${ }^{10}$ has recently made a critical assessment on previous experimental data on reactions involving solid $\mathrm{MnO}, \mathrm{MnS}, \mathrm{Mn}_{3} \mathrm{O}_{4}$, and $\mathrm{MnSO}_{4}$ in relation to those calculated from the thermochemical tables. His goal was to resolve some of the inconsistencies between the experimentally determined equilibrium constant of a reaction and that calculated from the thermochemical tables which may sometimes be so significant that the estimated value is uncertain by factors of two or more. Levels of uncertainty of this magnitude are not acceptable in the assessment of the equilibrium states of reactions in an industrial process such as the high temperature desulfurization of hot coal-derived fuel gases with manganese-based pellets.

The results from the various studies ${ }^{13,14,15}$ used in Turkdogan's analysis are reproduced in Figure 7, where the logarithm of the equilibrium constant $\left(\mathrm{pH}_{2} \mathrm{O} / \mathrm{pH}_{2} \mathrm{~S}\right)$ is plotted as a function of reciprocal temperature. By combining the experimental free energy data $\left(\Delta G_{r}\right)$ for $\mathrm{MnO}-\mathrm{MnS}$ reactions in the three studies outlined above and two additional studies ${ }^{16,17}$ with tabulated $\Delta G^{\circ}$ values for $\mathrm{SO}_{2}, \mathrm{H}_{2} \mathrm{O}$, and $\mathrm{H}_{2} \mathrm{~S}$, the $\Delta \mathrm{G}_{\mathrm{r}}$ values for the reaction

$$
M n O_{(s)}+\frac{1}{2} S_{2(g)}=M n S_{(s)}+\frac{1}{2} O_{2(g)}
$$

are obtained. These values are plotted in Figure 8 and are represented by lines $\mathrm{A}$ through $D$. Lines $E$ and $F$ are derived using the $\Delta G^{\circ}{ }_{M n O}$ data assessed by Coughlin ${ }^{18}$

$$
\Delta G^{\circ}{ }_{M n O}=-384840+73.14 T, \quad J \mathrm{~mol}^{-1}
$$

and two different assessments of $\Delta \mathrm{G}^{\circ}{ }_{\mathrm{MnS}}$ :

(i) values assessed by Cooper and Scarpiello ${ }^{19}$ and by Pankratz and King ${ }^{20}$ (ii) values derived from the thermodynamic data on inorganic sulfides, selenides, and tellurides compiled by Mills. ${ }^{21}$ 
Turkdogan ${ }^{10}$ gave more credence to line $\mathrm{F}$ since it lies in the middle range of the experimental results from two independent investigations using entirely different experimental techniques. The equation for line $\mathrm{F}$ is given by:

$$
\Delta G_{r}=106900-9.18 T, \quad J \mathrm{~mol}^{-1}
$$

Combining this equation with tabulated values for $\Delta \mathrm{G}_{\mathrm{H} 2 \mathrm{~S}}^{\mathrm{o}}$ and $\Delta \mathrm{G}_{\mathrm{H} 2 \mathrm{O}}^{\circ}$ gives the following equilibrium relation for the governing sulfidation reaction

$$
\begin{gathered}
\mathrm{MnO}_{(s)}+H_{2} S_{(g)}=M n S_{(s)}+H_{2} \mathrm{O}_{(g)} \\
\log \left(\frac{P_{\mathrm{H}_{2} \mathrm{O}}}{P_{\mathrm{H}_{2} S}}\right)=\frac{2557}{T}+0.204
\end{gathered}
$$

This equation is used for the solid line in Figure 7.

Several equilibrium measurements have been made of the dissociation partial pressures of $\mathrm{SO}_{2}$ and $\mathrm{O}_{2}$ in the reaction:

$$
\mathrm{MnSO}_{4(s)}=\frac{1}{3} \mathrm{Mn}_{3} \mathrm{O}_{4(s)}+\mathrm{SO}_{2(g)}+\frac{1}{3} \mathrm{O}_{2(g)}
$$

The results from different investigations ${ }^{15,17,22,23}$ are in general agreement, and the average of all the data may be represented by the following equation for temperatures in the range 900 to $1300{ }^{\circ} \mathrm{K}:{ }^{10}$

$$
\log k=\log P_{\mathrm{SO}_{2}}\left(P_{\mathrm{O}_{2}}\right)^{1 / 2}=-\frac{15625}{T}+11.888
$$

This equation is useful for the assessment of the thermodynamic feasibility of sulfate formation and may also be used to update previous thermodynamic analyses outlined by the authors.,

A number of $\mathrm{MnO} / \mathrm{MnS}$ equilibration tests were conducted using fresh FORM4-A pellets. The sulfidation gas consisted of a $3 \% \mathrm{H}_{2} \mathrm{~S}-\mathrm{H}_{2}$ mixture flowing at $2 \mathrm{~L} / \mathrm{min}$ and the temperature was varied from 800 to $1000{ }^{\circ} \mathrm{C}$. The average value of the logarithm of the equilibrium constant $\left(\mathrm{pH}_{2} \mathrm{O} / \mathrm{pH}_{2} \mathrm{~S}\right)$ obtained at the 
three temperatures studied is represented by a star-marked line on Figure 9. This figure also displays the error bars on the data to indicate the range of the results. The data from the present investigation may be represented by the following equation:

$$
\log \left(\frac{P_{H_{2} \mathrm{O}}}{P_{H_{2} S}}\right)=\frac{2151}{T}+0.659
$$

Acknowledgements. The authors express their appreciation to the Department of Energy, Morgantown Energy Technology Center, under Contract DE-AC2192MC29246 and also the U.S. Bureau of Mines, Twin Cities Research Center, Grant USDI-BM/C0299002-Mod.3 for providing support for this study. Thanks are also extended to Kent Wagner and Rick Stuart for their help with the experimental work.

\subsection{References}

1. Hepworth, M. T.; Ben-Slimane, R.; Zhong, S. Thermodynamic Comparison of Several Sorbent Systems for Hot Coal-Derived Fuel-Gas Desulfurization. Energy \& Fuels, 1993, 7, 602-609.

2. Westmoreland, P.R.; Harrison, D.P. Evaluation of Candidate Solids for High-Temperature Desulfurization of Low-Btu Gases. Env. Sci. \& Tech., Vol. 10, No. 7, July, 1976, pp. 659-661.

3. Westmoreland, P.R.; Gibson, J.B.; Harrison, D.P. Comparative Kinetics of High-Temperature Reaction Between $\mathrm{H}_{2} \mathrm{~S}$ and Selected Metal Oxides. Env. Sci. \& Tech, Vol. 11, No. 5, May, 1977, pp. 488-491.

4. Woods M. C. et al. Reaction between $\mathrm{H}_{2} \mathrm{~S}$ and Zinc-Oxide-Titanium Oxide Sorbents. 1. Single-Pellet Kinetic Studies. I\&EC RESEARCH, 1990, pp. 1160-1167.

5. Jha, M. C.; Blandon, T.; Hepworth, M. T. Durable Zinc Ferrite Sorbent 
Pellets for Hot Coal Gas Desulfurization. U.S. Patent No. 4,732,888, March 22, 1988.

6. Ben-Slimane, R.; Hepworth, M. T. Desulfurization of Hot Coal-Derived Fuel Gases with Manganese-Based Regenerable Sorbents. 1. Loading (Sulfidation) Tests, Accepted for Publication in the Nov/Dec issue of Energy \& Fuels, 1994,.

7. Ben-Slimane, R.; Hepworth, M. T. Desulfurization of Hot Coal-Derived Fuel Gases with Manganese-Based Regenerable Sorbents. 2. Regeneration and Multicycle Tests, Accepted for Publication in the Nov/Dec issue of Energy \& Fuels, 1994,.

8. Hepworth, M. T.; Ben-Slimane, R. Hot Coal Gas Desulfurization with Manganese-Based Sorbents. DE-AC21-92MC29246.

9. Notestein, J. E. Commercial Gasifier for IGCC Applications Study Report, DOE/METC-91/6118 (DE91002051), June 1990.

10. Turkdogan, E. T. Synchronising free energy data on reactions in liquid FeMn-O and solid Mn-S-O systems. Ironmaking \& Steelmaking 1993, Vol. 20 No. 6, pp. 469-475.

11. Ben-Slimane, R.; Hepworth, M. T. Regenerable Manganese-Based Sorbent Pellets and Methods of Manufacture and Use. Patent Application Filed in the U.S. Patent and Trademark Office, June 17, 1994.

12. O’Donnell, J. J.; Katta, S.; Grindley, T.; Delzer, G.; Khare, G.

Desulfurization of Hot Fuel Gas with Z-Sorb III Sorbent, Proceedings of the Coal-Fired Power Systems 93 -- Advances in IGCC and PFBC Review Meeting, 1993; Bonk, David L., Ed.; DOE/METC-93/6131; NTIS: Springfield, VA, 1993; 179-190.

13. Dewing, E. W.; Richardson, F. D.: J. Iron Steel Inst., 1960, 195, 56.

14. Turkdogan, E. T.; Olsson, R. G. Desulfurization of Hot Reducing Gases with Manganese Oxide Pellets. Proceedings of the Third International Iron and Steel Congress ASM; ASM International : Materials Park, OH, 1979; pp 
277-288.

15. Turkdogan, E. T.; Olsson, R. G.; Vinters, J. V. Sulfate and Sulfide Reactions in the Mn-S-O System, Metall. Trans., 1977, 8B, 59-65.

16. Larson, H. R.; Elliott, J. F. The Standard Free Energy of Formation of Certain Sulfides of Some Transition Elements and Zinc, Trans. AIME, 1967, 239, 1713-1720.

17. Huang, J. H.; Rosen, E. Solid state emf studies of equilibria in the Mn-S-O system at $900 \mathrm{~K}-1300 \mathrm{~K}$ Scand. J. Metall., 1992, 21, (3), 116-120.

18. Coughlin, J. P.: U.S. Bur. Mines Bull., 1954, 542.

19. Cooper, W. J.; Scarpiello, D. A. Thermodynamic properties of metal borides, iodides, sulfides, sulfates, chromates, metaphosphates, molybdates, tungstates, borates, and hydroxides, Report SC-RR-64-67, Sandia Corp. (for U.S. Atomic Energy Commission), Palo Alto, CA, 1964.

20. Pankratz, L. B.; King, E. G. High-temperature heat contents and entropies of two zinc sulfides and four solid solutions of zinc and iron sulfides. U.S. Bur. Mines Rep. Invest., 1965, 6708.

21. Mills, K. C.: Thermodynamic data for inorganic sulfides, selenides, and tellurides, 1974, London, Butterworths.

22. Skeaff, J. M.; Espelund, A. W. An E.M.F. method for the determination of sulphate-oxide equilibria results for the $\mathrm{Mg}, \mathrm{Mn}, \mathrm{Fe}, \mathrm{Ni}, \mathrm{Cu}$ and $\mathrm{Zn}$ systems. Can. Metall. Q., 1973, 12, 445-454.

23. Ingraham, T. R. Thermodynamics of the Mn-S-O system between $1000{ }^{\circ} \mathrm{K}$ and $1250^{\circ} \mathrm{K}$, Can. Metall. Q., 1966, 5, 109-122. 
List of Figures.

Figure 1. Schematic diagram of overall experimental arrangement for fixedbed tests.

Figure 2. Schematic diagram of fixed-bed reactor details.

Figure 3. Breakthrough curve for sulfidation at $900{ }^{\circ} \mathrm{C}$ (cycle No. 1) of FORM4-A pellets using a Tampella $U$ fuel gas at $3 \mathrm{~L} / \mathrm{min}$.

Figure 4. Breakthrough curve for regeneration at $900{ }^{\circ} \mathrm{C}$ (cycle No. 2) of loaded FORM4-A pellets using air at $1 \mathrm{~L} / \mathrm{min}$.

Figure 5. Breakthrough curves for sulfidation at $900{ }^{\circ} \mathrm{C}$ (cycles $1,2,3$, and 6) of FORM4-A pellets using a Tampella $U$ fuel gas at $3 \mathrm{~L} / \mathrm{min}$ and air at $1 \mathrm{~L} / \mathrm{min}$ for regeneration.

Figure 6. Effect of cyclic loading and regeneration on sulfur capacity of FORM4-A pellets at $900{ }^{\circ} \mathrm{C}$.

Figure 7. Comparison of experimental data on reaction equilibrium $\mathrm{MnO}+$ $\mathrm{H}_{2} \mathrm{~S}=\mathrm{MnS}+\mathrm{H}_{2} \mathrm{O}$ with those calculated from compiled thermochemical tables. ${ }^{10}$

Figure 8. Experimental $\left(\mathrm{A},{ }^{16} \mathrm{~B},{ }^{17} \mathrm{C},{ }^{14,15} \mathrm{D}^{13}\right)$ and calculated $\left(\mathrm{E},{ }^{19,20} \mathrm{~F}^{21}\right)$ free energy data for the reaction $\mathrm{MnO}+1 / 2 \mathrm{~S}_{2}=\mathrm{MnS}+1 / 2 \mathrm{O}_{2}{ }^{10}$

Figure 9. Comparison of experimental data obtained in this investigation on sulfidation reaction equilibrium with those of Turkdogan and Olsson $^{14}$ and the equation recently recommended by Turkdogan. ${ }^{10}$ 


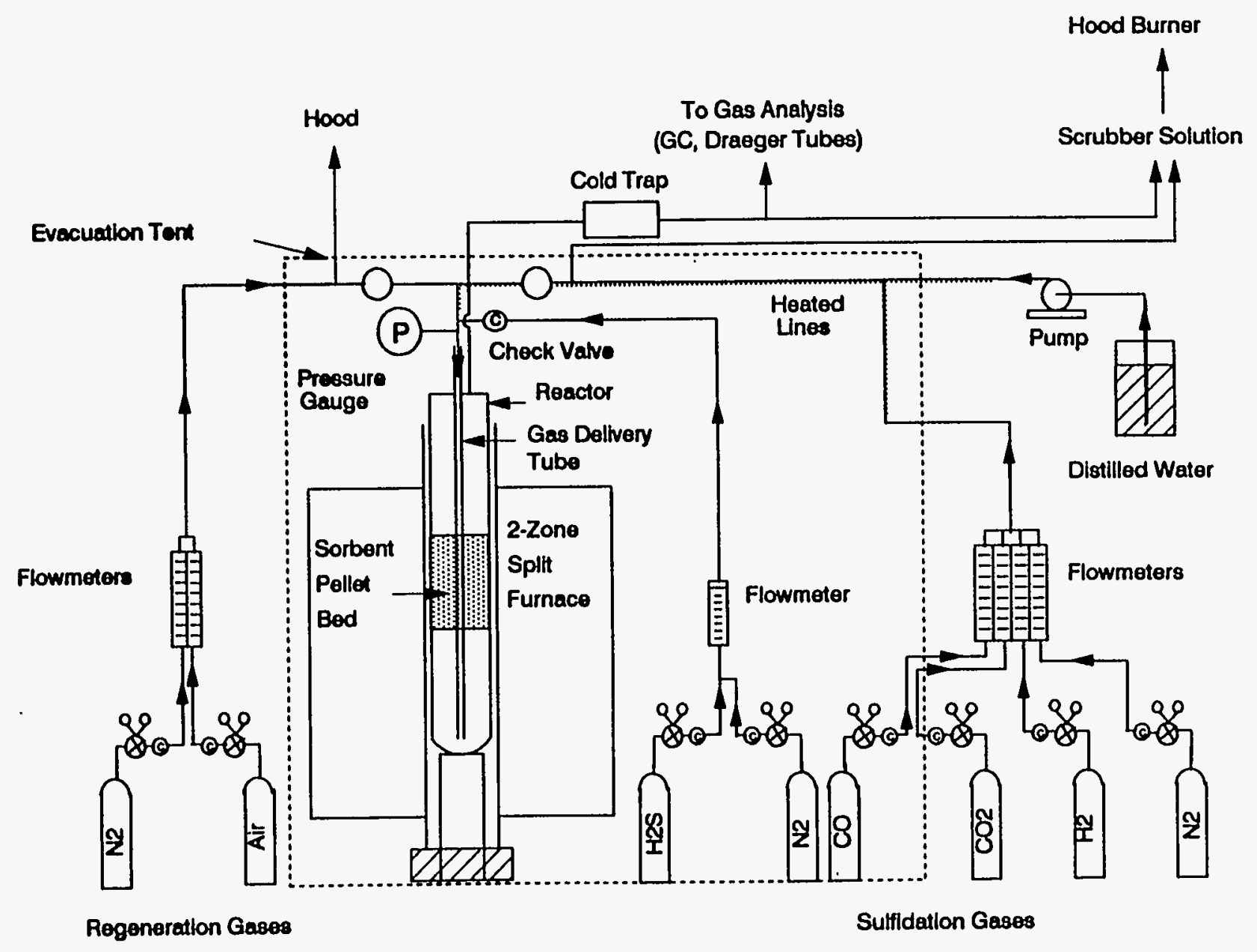

FIGURE 1 


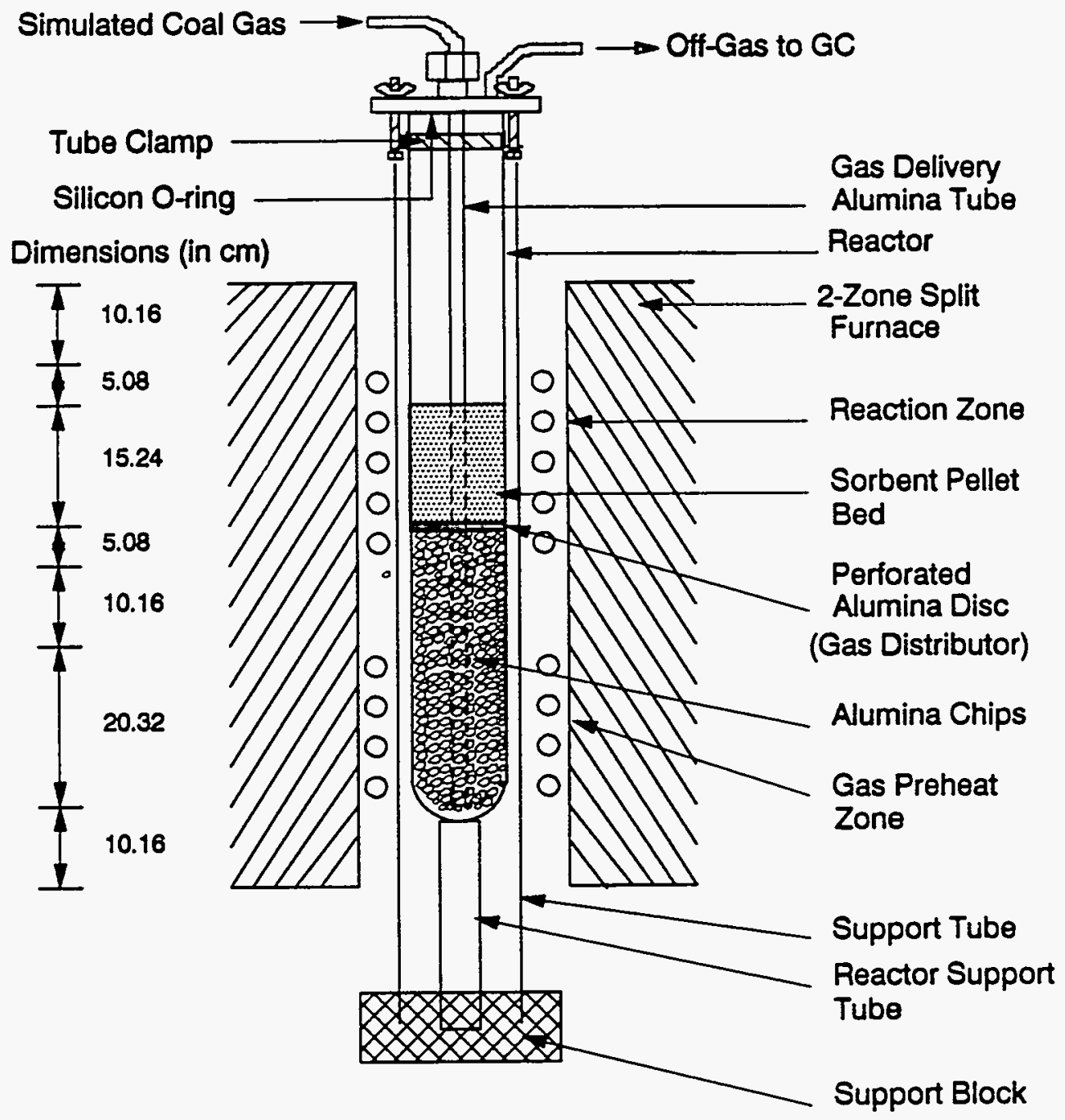




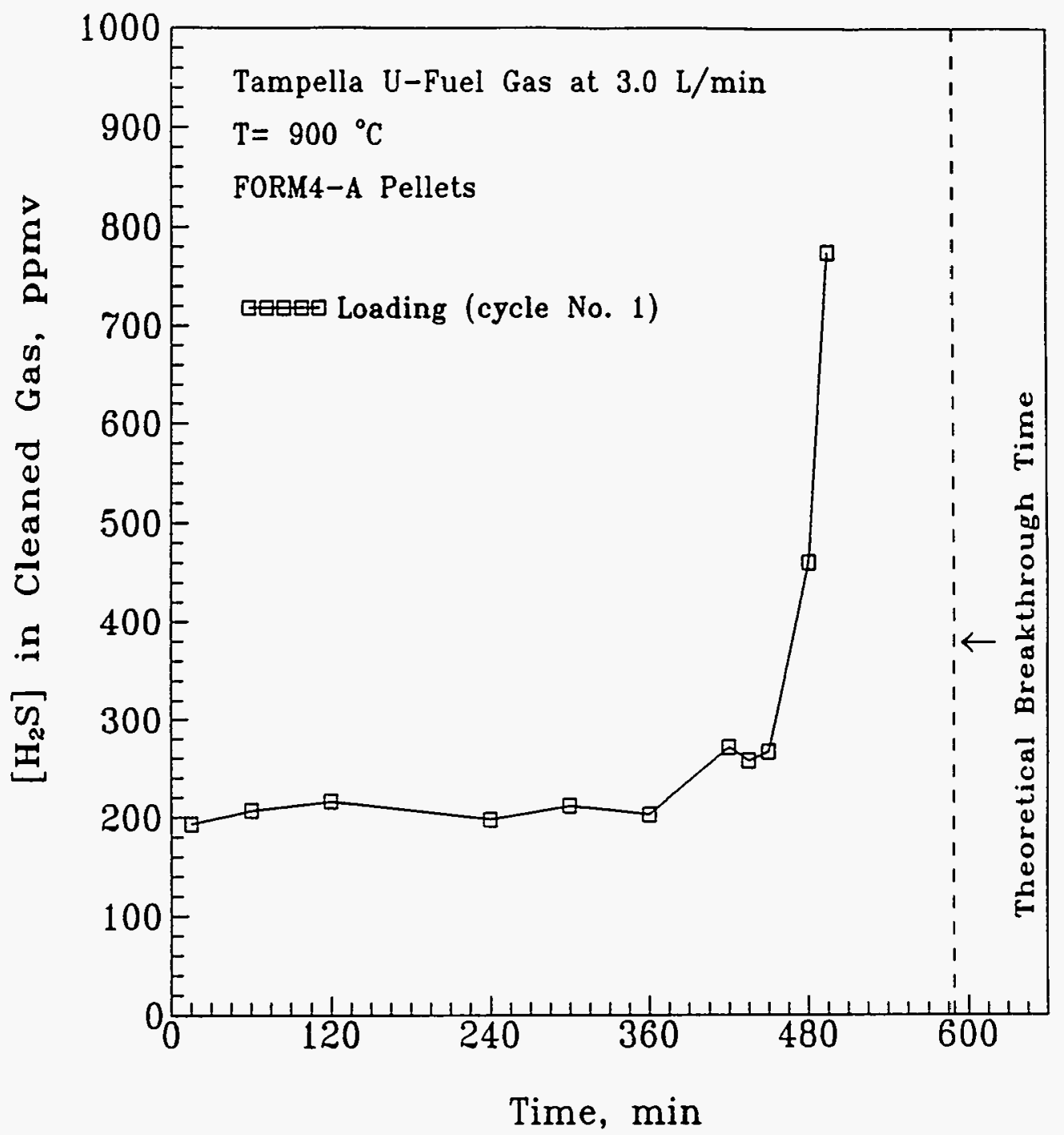

FIGURE 3 


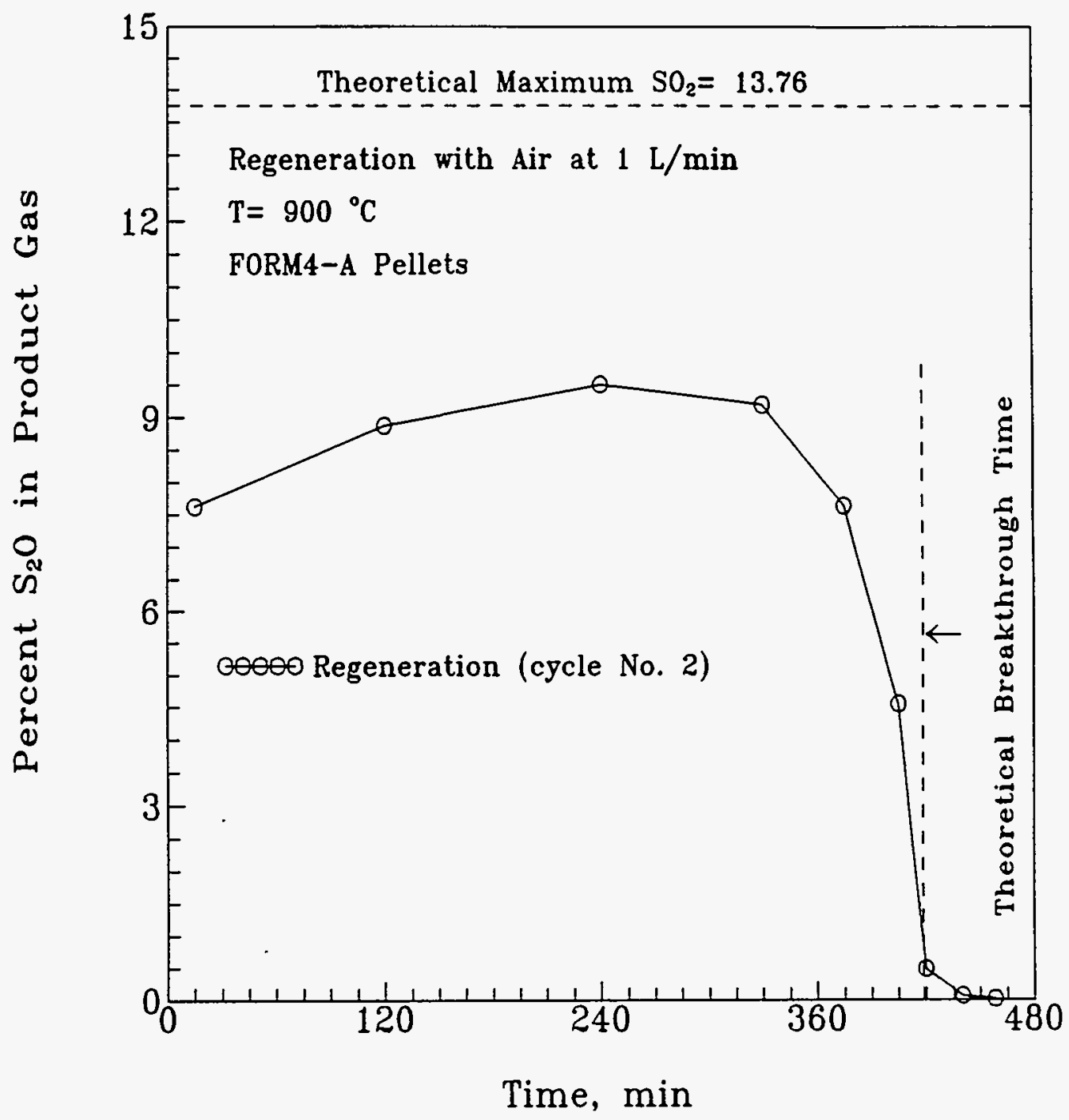

FIGURE 4 


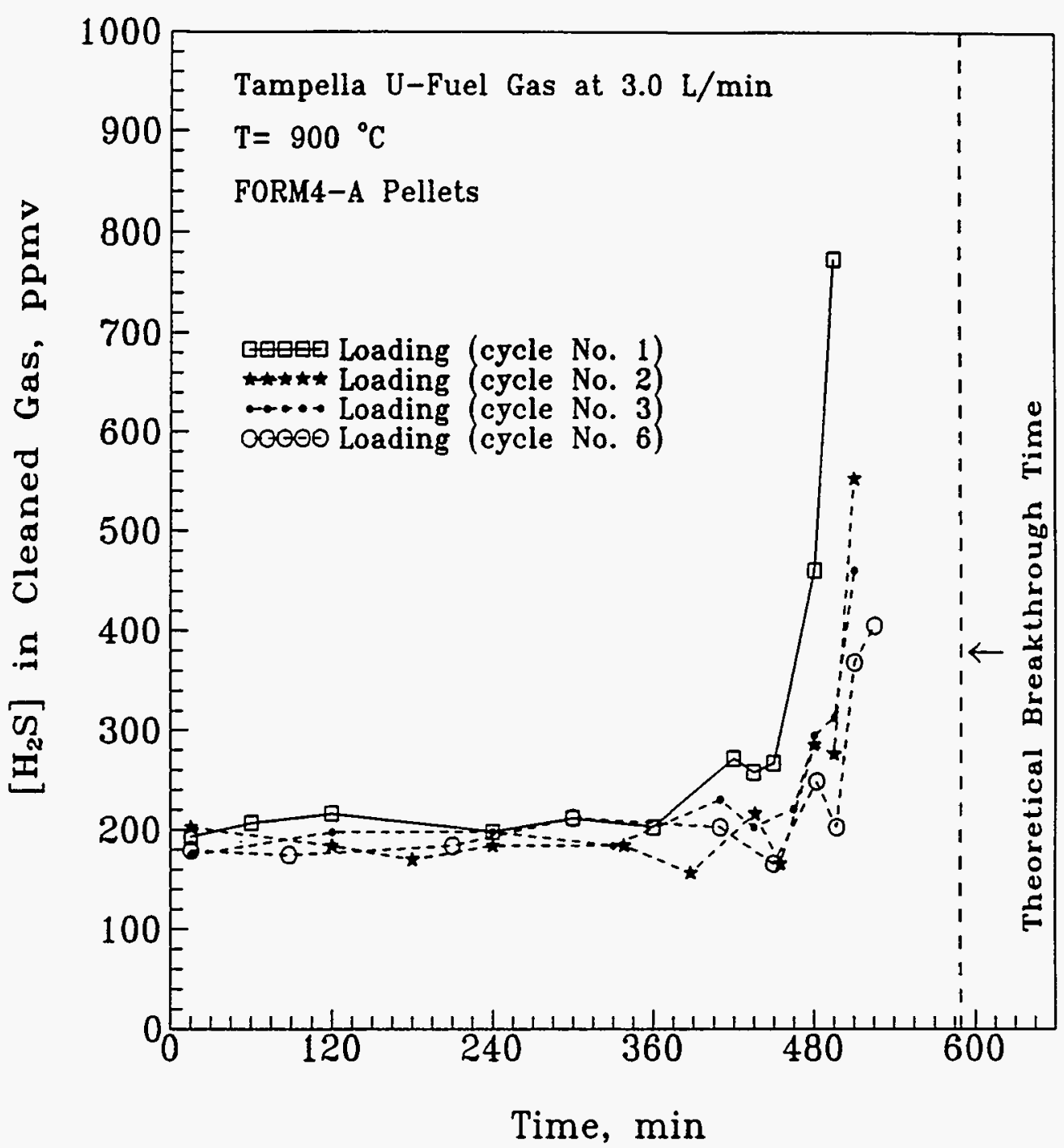

FIGURE 5 


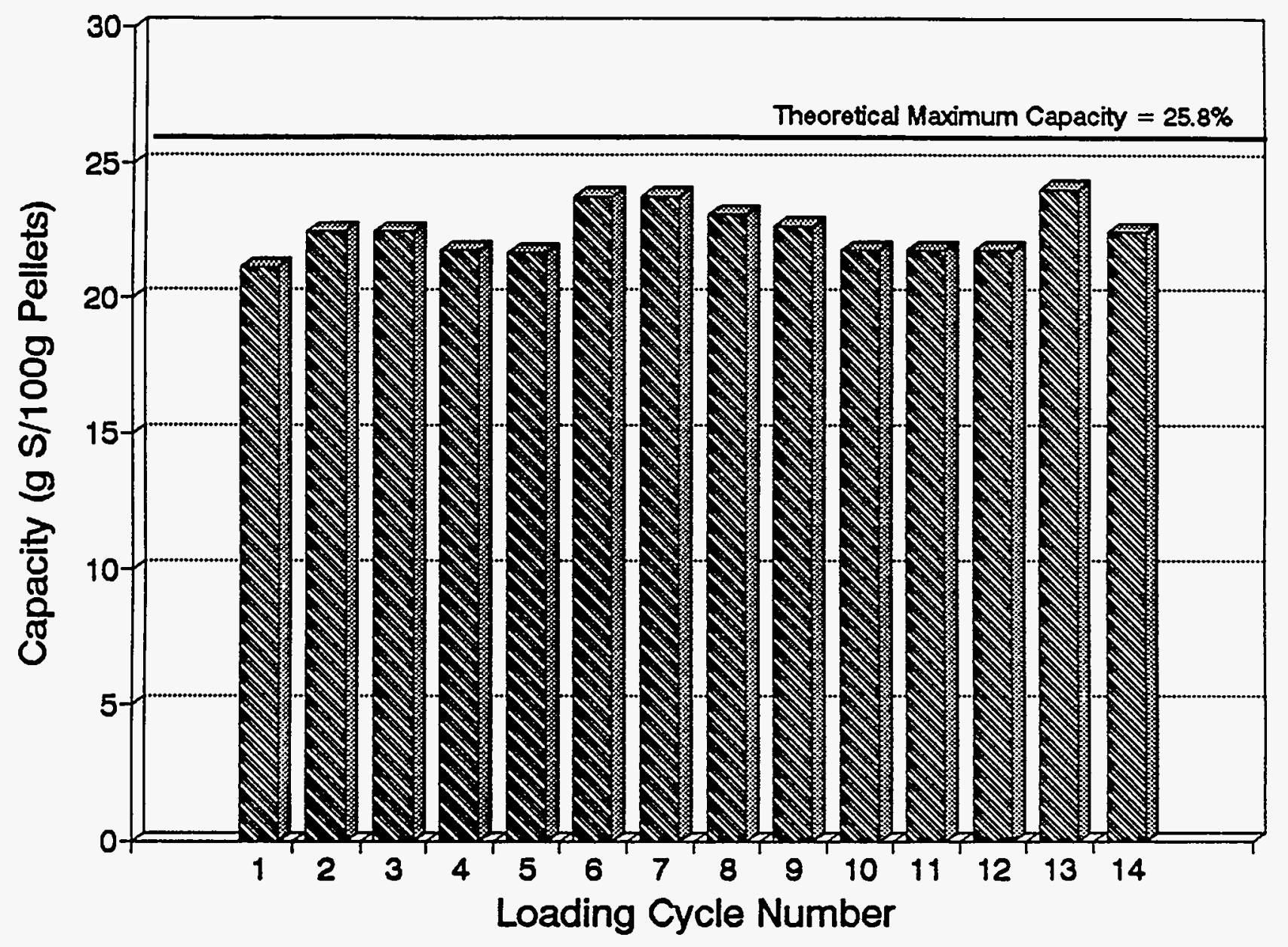

FIGURE 6 


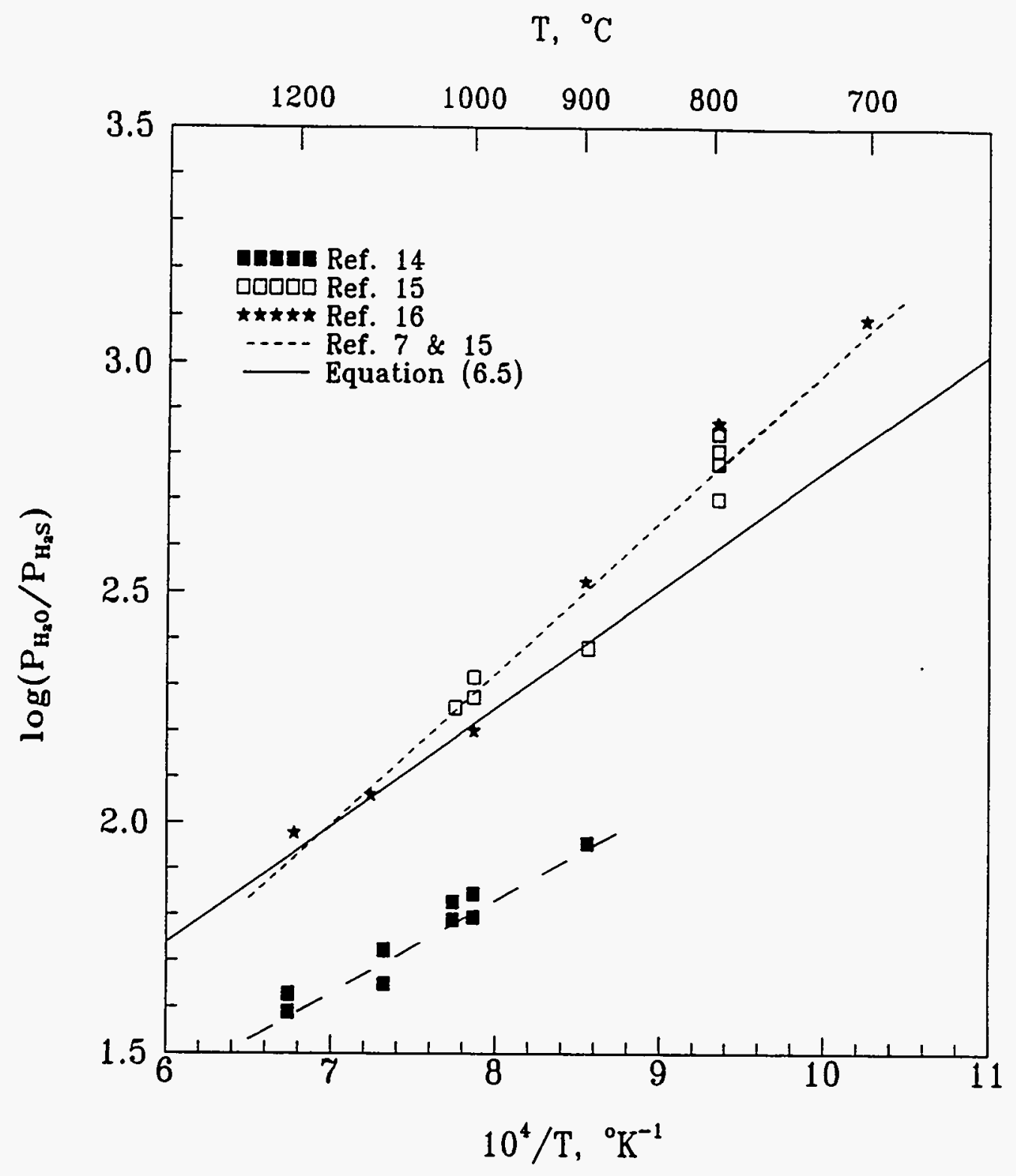

FIGURE 7 


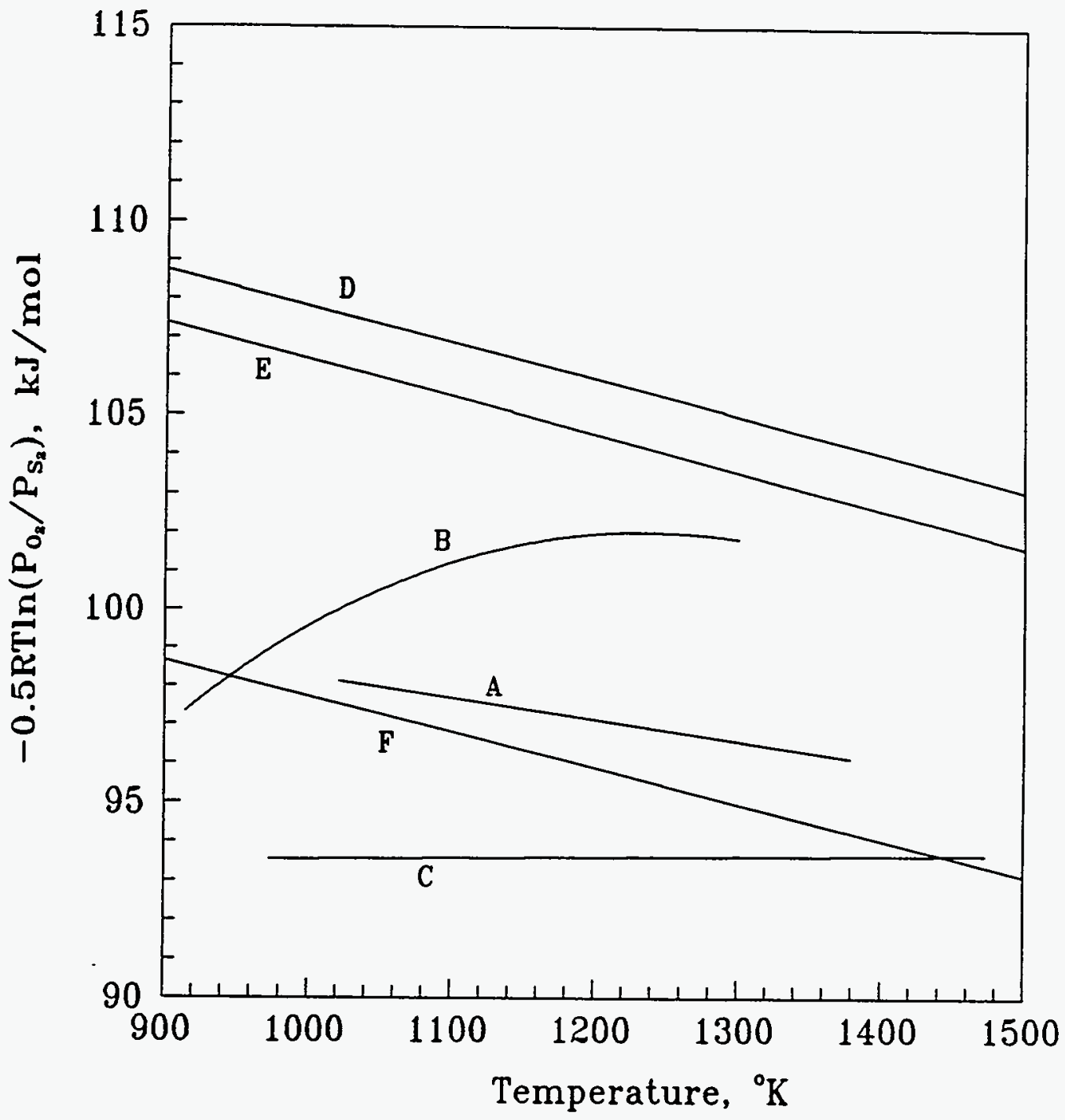

FIGURE 8 